\title{
Effect of an injectable trace mineral supplement containing selenium, copper, zinc, and manganese on immunity, health, and growth of dairy calves
}

\author{
A. G. V. Teixeira, F. S. Lima, M. L. S. Bicalho, A. Kussler, S. F. Lima, M. J. Felippe, and R. C. Bicalho ${ }^{1}$ \\ Department of Population Medicine and Diagnostic Sciences, College of Veterinary Medicine, Cornell University, Ithaca, NY 14853
}

\begin{abstract}
The objective of this study was to evaluate the effect of 2 subcutaneous injections of a multimineral preparation, each containing $60 \mathrm{mg}$ of zinc, $10 \mathrm{mg}$ of manganese, $5 \mathrm{mg}$ of selenium, and $15 \mathrm{mg}$ of copper at 3 and 30 d after birth on immunity, health, and growth of dairy calves during the preweaning period. The study was conducted in upstate New York in 2 commercial dairy farms. A total of 790 Holstein heifer calves were randomly allocated at birth into 1 of 2 treatments: trace mineral supplement (TMS) treated or control. Blood samples were collected at 3,14 , and $35 \mathrm{~d}$ after birth to evaluate glutathione peroxidase (GPx) activity, superoxide dismutase (SOD) activity, haptoglobin, and neutrophil and monocyte function. Incidence of diseases and average daily gain was evaluated in the first $50 \mathrm{~d}$ of life. At $14 \mathrm{~d}$ of life, TMS-treated calves had increased neutrophil activity compared with control calves. Moreover, TMS-treated calves had greater GPx activity on d 14 after birth than control calves. The TMS treatment reduced the incidence of diarrhea (TMS $=41.7 \%$ vs. control $=49.7 \%)$ and combined incidence of pneumonia or otitis or both (TMS $=41.7 \%$ vs. control $=49.1 \%$ ). Additionally, GPx was greater for calves diagnosed with otitis at d 35 after birth. However, calves diagnosed with pneumonia had decreased GPx activity at d 35 after birth. Serum SOD and haptoglobin concentrations were not affected by treatment or disease. Moreover, no effects were observed on average daily gain and survivability between TMS-treated and control calves during the preweaning period. Supplementation with trace minerals at 3 and $30 \mathrm{~d}$ of life increased neutrophil function and GPx activity and reduced the incidence of health disorders.
\end{abstract}

Key words: trace mineral, dairy calf, neutrophil function, diarrhea

Received October 19, 2013.

Accepted March 16, 2014.

${ }^{1}$ Corresponding author: rcb28@cornell.edu

\section{INTRODUCTION}

Dairy replacement rearing success or failure is dependent on several complex and interrelated factors. Newborn calf health and growth can be impaired by poor maternal health (Lundborg et al., 2003), dystocia (Lombard et al., 2007), colostrum deprivation (Weaver et al., 2000), and poor calf nutrition (Ollivett et al., 2012). In the modern dairy industry, calves are reared artificially and early nutritional programs have been extensively studied to improve their performance during the preweaning period (Soberon et al., 2012). The physiological processes of a livestock animal, including the immune system, can be largely influenced by the availability of nutrient and trace minerals that are essential for multiple biochemical processes, including immune response, cell replication, and skeletal development, and are particularly relevant for the newborn (Carroll and Forsberg, 2007).

Studies that evaluate trace mineral depletion or supplementation focus on critical times in calves' lives and evaluate the effects of factors such as transportation (Crookshank et al., 1979), stress (Galyean et al., 1999), and diseases (Orr et al., 1990). For adult cattle, stress during the transition period can affect trace mineral status (zinc) and immune suppression can lead to greater susceptibility to diseases (Enjalbert et al., 2006). Likewise, stress can affect trace mineral status in dairy calves. Nockels et al. (1993) reported that calves under induced stress (intramuscular injections of $\mathrm{ACTH}$ ) reduced their ability to retain trace minerals. An injectable trace mineral solution containing Zn, $\mathrm{Cu}, \mathrm{Mn}$, and Se was reported to increase liver concentrations of $\mathrm{Cu}$ and Se for at least a 15-d period, and increased plasma Zn and Mn for several hours in Angus and Simmental steers (Pogge et al., 2012).

Metabolic demands associated with stress and nutritional deficiency can lead to an increased production of reactive oxygen species (ROS; Sordillo and Aitken, 2009). When the production of ROS exceeds the antioxidant defense mechanisms present in the body, animals develop oxidative stress. Reactive oxygen species can initiate lipid peroxidation and cause cellular damage to tissues. Immune cells are particularly sensitive to oxidative stress because their membranes contain high 
concentrations of PUFA that are very susceptible to peroxidation, and produce large amounts of ROS when stimulated (Spears and Weiss, 2008). Several trace minerals are required for functioning of enzymes involved in the antioxidant defense system and may also affect immune cells via mechanisms distinct from antioxidant properties (Spears, 2000).

The role of early postnatal supplementation with injectable trace minerals on the immune response of newborn calves has not been investigated. Therefore, the objectives of this study were to evaluate the effect of supplementation of an injectable multimineral supplement containing $\mathrm{Zn}, \mathrm{Mn}$, Se, and $\mathrm{Cu}$ at 3 and $30 \mathrm{~d}$ after birth on peripheral blood neutrophil and lymphocyte function, oxidative stress markers, diseases (diarrhea, pneumonia, and otitis), and growth of Holstein heifer calves during the preweaning period.

\section{MATERIALS AND METHODS}

The study was conducted in 2 commercial dairy farms located near Ithaca, New York, from February to December, 2012. Farms were chosen because of their relationship with the Cornell University Ambulatory Clinic. Farm A was milking approximately 2,800 cows and farm B was milking approximately 1,600 cows.

Colostrum management was similar in both farms. Colostrum from primiparous and multiparous cows was pooled and refrigerated. Calves from farm A were fed approximately $4 \mathrm{~L}$ of raw colostrum within $4 \mathrm{~h}$ of birth at once by esophageal feeder (Oral Calf Feeder Bag with Probe; Jorvet; Jorgensen Laboratories, Loveland, $\mathrm{CO})$. Calves from farm $\mathrm{B}$ were fed $2 \mathrm{~L}$ of raw colostrum within $2 \mathrm{~h}$ and another $2 \mathrm{~L}$ approximately $6 \mathrm{~h}$ later.

Both study farms had similar calf-rearing systems, which were individual pens in a greenhouse-type barn, positive ventilated, with individual pen dimensions of $1.5 \mathrm{~m}$ wide by $2 \mathrm{~m}$ long. The individual pens were isolated by plastic panels and bedded with a 0.5-m-deep gravel base that was covered with straw. Farm A and $\mathrm{B}$ had the same feeding system: calves were fed a total of $6 \mathrm{~L}$ of pasteurized $\left(72^{\circ} \mathrm{C}\right.$ for $15 \mathrm{~s}$; T-600 and T-300; Goodnature Products Inc., Orchard Park, NY) nonsalable milk divided equally twice per day (0630 and 1700 h). Water and calf starter diets were offered ad libitum starting at d 3 of life to all calves in farms A and B. The starter composition for both farms is described in Table 1.

\section{Study Design, Treatments, Blood Sampling, and Data Collection}

A total of 790 calves were randomly allocated into the 2 treatments: trace mineral supplement (TMS)
Table 1. Nutrient composition of calf starter diets for farms A and B

\begin{tabular}{lcc}
\hline & \multicolumn{2}{c}{ Starter diet } \\
\cline { 2 - 3 } Composition & Farm A & Farm B \\
\hline DM (\%) & 82.1 & 90.9 \\
CP (\% of DM) & 19.8 & 22.9 \\
NDF (\% of DM) & 29.4 & 31.8 \\
ADF (\% of DM) & 15.7 & 14.1 \\
TDN (\% of DM) & 72 & 77 \\
Ca (\% of DM) & 0.99 & 0.94 \\
P (\% of DM) & 0.64 & 0.78 \\
Mg (\% of DM) & 0.43 & 0.35 \\
K (\% of DM) & 1.40 & 1.01 \\
Na (\% of DM) & 0.35 & 0.39 \\
S (\% of DM) & 1.28 & 0.35 \\
Fe (mg/kg) & 398 & 258 \\
Zn (mg/kg) & 65 & 111 \\
Cu (mg/kg) & 20 & 22 \\
Mo (mg/kg) & 66 & 100 \\
\hline
\end{tabular}

treatment or control. Randomization was completed using the random number function in Excel software (Microsoft Corp., Redmond, WA). Calves allocated into the TMS treatment received two 1-mL subcutaneous injections (60 mg of $\mathrm{Zn}, 10 \mathrm{mg}$ of $\mathrm{Mn}, 5 \mathrm{mg}$ of Se, and $15 \mathrm{mg}$ of $\mathrm{Cu}$; Multimin North America Inc., Fort Collins, CO) at 3 and $30 \mathrm{~d}$ after birth. Calves allocated into the control group were left untreated. Body weight was measured weekly in both farms using a WayPig 15, 1.6-m (62-inch) digital scale (WayPig; Vittetoe Inc., Keota, IA) from birth until weaning, which occurred at $50 \mathrm{~d}$ of life.

Blood collection was performed via jugular venipuncture using an 18-gauge by $3.8-\mathrm{cm}$ needle in 2 individual vacuum tubes: a $10-\mathrm{mL}$ vacuum tube (Becton, Dickinson and Co., Franklin Lakes, NJ) without anticoagulant for serum and an 8-mL heparinized vacuum tube (Becton, Dickinson and Co.) for plasma. Serum was harvested following centrifugation at 2,000 $\times g$ for 15 min at $4^{\circ} \mathrm{C}$ and plasma was harvested after centrifugation at $1,000 \times g$ for $10 \mathrm{~min}$ at $4^{\circ} \mathrm{C}$. Serum and plasma samples were stored at $-80^{\circ} \mathrm{C}$. Blood was sampled on d 3 (immediately before treatment administration), 14, and 35 after birth to evaluate glutathione peroxidase (GPx), superoxide dismutase (SOD), and haptoglobin (Hp). Additionally, serum IgG concentration was measured only on d 3 .

A random subset of serum samples from 10 calves (5 for treatment) were sent to Veterinary Diagnostic Laboratory, Iowa State University (Ames) for analysis of $\mathrm{Ca}, \mathrm{Cu}, \mathrm{Fe}, \mathrm{K}, \mathrm{Mg}, \mathrm{Mn}$, Mo P, Se, and Zn. Blood mineral levels were measured at 3,14 , and $35 \mathrm{~d}$ after birth. The concentrations of serum trace elements were analyzed by an inductively coupled plasma mass spectrometry (ICP-MS) system (Varian/Bruker 820 ICP-MS; Bruker Corp., Fremont, CA) through separation of analyte ions from spectral interferences. Serum 
mineral concentrations were reported in milligrams per kilogram.

Serum IgG was measured using a radial immunodiffusion assay according to kit instructions (Bethyl Laboratories Inc., Montgomery, TX). Intraassay and interassay coefficients of variation for IgG were 3.2 and $3.6 \%$, respectively. An SOD assay kit (Cayman Chemical Co., Ann Arbor, MI) was used, following the manufacturer's instructions for assaying SOD activity in plasma. The intraassay coefficient of variation for SOD was 3.7\%. Likewise, a Cayman GPx assay kit was used, following the manufacturer's instructions to evaluate GPx activity. The intraassay coefficient of variation for GPx was $7.2 \%$. Serum Hp was evaluated following the method described by Makimura and Suzuki (1982). The intraassay coefficient of variation for Hp was $9.8 \%$.

Additionally, a random subset of 228 calves (112 control and 126 TMS-treated calves) from one of the farms was sampled to evaluate neutrophil and monocyte function at d 14 after birth. Neutrophil and monocyte function was measured by the neutrophil and monocyte phagocytic activity using a PHAGOTEST kit (Orpegen Pharma GmbH, Heidelberg, Germany) containing fluorescein-labeled opsonized Escherichia coli (E. coliFITC), following the manufacturer's instructions. Cells were analyzed with a FACSCalibur flow cytometer (Becton, Dickinson and Co.) using a 488-nm argon-ion laser. Ten thousands events were collected for each cell population (neutrophils or monocytes). The results are reported as the percentage of cells performing phagocytosis from the total number of cells in the granulocyte gate and as the increase mean of the green fluorescence of the gated cells.

\section{Case Definitions}

All diseases were diagnosed by the farm personnel according to guidelines and training provided by the Ambulatory Production Medicine Service from Cornell University. Pneumonia was determined by the identification of 2 or more of the following clinical signs: cough, rectal temperature $>39.5^{\circ} \mathrm{C}$, respiratory rate $>40$ breaths/min, and increased cranioventral lung sounds or wheezes. Otitis was defined by observation of ear pain, evidenced by head shaking, scratching or rubbing the ears, epiphora, ear droop, and signs of facial nerve paralysis, combined with fever $\left(>39.5^{\circ} \mathrm{C}\right)$. Calves were recorded as diarrheic when diarrhea (watery feces) was observed at least during 3 consecutive days.

\section{Statistical Analyses}

Descriptive statistics were performed using PROC FREQ, MEANS, and UNIVARIATE of SAS (SAS In- stitute Inc., Cary, NC). The initial BW, IgG concentrations at d 3 after birth, percentage of calves born from primiparous cows, and assisted parturition percentage were evaluated to ensure similar distribution between TMS-treated and control calves within each farm and rearing systems.

For all health events [pneumonia; otitis; diarrhea; combined incidence of pneumonia, otitis, or both (CPO); and mortality] calves were right censored at the end of the study period ( $50 \mathrm{~d}$ of life). To evaluate the effect of treatment on pneumonia, otitis, diarrhea, $\mathrm{CPO}$, and mortality, 5 multivariable mixed logistic regression models were fitted with a binary distribution and the logit link to the data using PROC GLIMMIX of SAS. An autoregressive covariance structure was used for the multivariable models. The variables treatment group, serum IgG concentration (3 d of life), and birth weight were included in all models. Additionally, the variable farm was included in all models as a random effect. Adjusted proportions of pneumonia, otitis, diarrhea, $\mathrm{CPO}$, and mortality were obtained using the LSMEANS statement.

The effect of treatment on ADG and neutrophil and monocyte function was evaluated with linear mixed models using PROC MIXED of SAS. Average daily gain was calculated by subtracting the BW at weaning (50 d of life) by the birth weight, and subsequently dividing by 50. Farm effect was evaluated in the models and because no effects of farm were present, it was used as a random effect. Birth weight and serum IgG concentration at $3 \mathrm{~d}$ of life were used as independent variables. Least squares means and respective 95\% confidence intervals were estimated for all categorical main effects.

Linear mixed models were fitted to the data using PROC MIXED of SAS to analyze the effect of treatment, pneumonia, otitis, and mortality from the repeated measures $(3,14$, and $35 \mathrm{~d}$ of life) on blood minerals, GPx, SOD, and Hp. To control for repeated measures, the animal identification number (nested within farm) was included in all models as a random effect and serum IgG concentration (3 d of life) and birth weight were included as covariates. Separate models were used for treatment, pneumonia, otitis, and mortality to avoid multicollinearity. The interaction of each categorical variable and sampling time were offered to all models.

For all linear mixed models, the assumption that the residuals were normally distributed was assessed by visually evaluating the distribution plot of the studentized residuals. Statistical significance was declared at $P \leq 0.05$ and statistical tendencies were declared at $0.05<P \leq 0.10$. 
Table 2. Percentage of calves born from primiparous cows, assisted parturition percentage, initial BW (kg), and calf serum IgG concentrations at d 3 after birth (g/L), evaluated between trace mineral supplement (TMS)-treated ${ }^{1}$ and control calves within the farm rearing systems ${ }^{2}$

\begin{tabular}{|c|c|c|c|c|c|c|}
\hline \multirow[b]{2}{*}{ Item } & \multicolumn{3}{|c|}{ Farm A treatment } & \multicolumn{3}{|c|}{ Farm B treatment } \\
\hline & Control & TMS & $P$-value & Control & TMS & $P$-value \\
\hline Calves born to primiparous cows (\%) & 34 & 33 & 0.92 & 43 & 45 & 0.79 \\
\hline Assisted parturition (\%) & 4 & 5 & 0.43 & 16 & 18 & 0.78 \\
\hline Initial $\mathrm{BW}^{3}$ & $38.1(0.3)$ & $38.3(0.3)$ & 0.65 & $41.3(0.6)$ & $41.1(0.6)$ & 0.79 \\
\hline Serum $\operatorname{IgG}^{4}$ & $23.2(0.9)$ & $23.8(0.9)$ & 0.59 & $26.7(1.8)$ & $25.7(1.6)$ & 0.69 \\
\hline
\end{tabular}

${ }^{1}$ The TMS-treated calves were treated at 3 and $30 \mathrm{~d}$ of age.

${ }^{2}$ The LSM and the respective SEM (in parentheses) are presented for initial BW and serum IgG concentration.

${ }^{3}$ Calf initial BW $(\mathrm{kg})$ at $3 \mathrm{~d}$ of life.

${ }^{4}$ Calf serum IgG concentration $(\mathrm{g} / \mathrm{L})$ measured at $3 \mathrm{~d}$ of life, before the first treatment.

\section{RESULTS}

\section{Descriptive Statistics}

Average BW (kg) at enrollment, serum IgG concentration at $3 \mathrm{~d}$ of life, percentage of calves born to primiparous cows, percentage of assisted parturitions, and number of calves enrolled in each calf farm by rearing system were not different for calves on TMS and control treatments (Table 2).

\section{Blood Minerals, Disease Incidence and ADG}

Serum mineral concentrations analyzed revealed that $\mathrm{Ca}, \mathrm{Cu}, \mathrm{Fe}, \mathrm{K}, \mathrm{Mg}, \mathrm{Mn}, \mathrm{Mo}, \mathrm{P}, \mathrm{Se}$, and $\mathrm{Zn}$ concentrations were not different for TMS-treated and control calves at d 3 after birth (baseline), right before the first TMS treatment was conducted (Figure 1). On d 14 after birth, TMS-treated calves had increased concentrations of Se $(P<0.01)$ and $\mathrm{Zn}(P<0.01)$ compared with counterpart control calves (Figure 1). At d 14 after birth, serum concentrations of $\mathrm{Ca}, \mathrm{Cu}, \mathrm{Fe}, \mathrm{K}, \mathrm{Mg}$, $\mathrm{Mn}, \mathrm{Mo}$, and $\mathrm{P}$ did not differ between TMS-treated and control calves (Figure 1). Moreover, no difference was detected between TMS-treated and control calves for any of the minerals evaluated at d 35 after birth (Figure 1).

The effect of treatment on adjusted incidences of mortality, diarrhea, otitis, pneumonia, and CPO is presented on Table 2. Briefly, TMS-treated calves had lower $(41.7 \%)$ incidence of diarrhea compared with control group calves (49.1\%; $P=0.034$; Table 2). Additionally, control calves were at a 1.35 (range of 1.00-1.83) higher odds of CPO compared with calves in the TMS-treated group $(P=0.05)$. However, ADG was not significantly different between treatment groups $(P$ $=0.49$ ). The ADG for TMS-treated calves was $778 \mathrm{~g} / \mathrm{d}$ $(95 \% \mathrm{CI}=729-826)$ and $789 \mathrm{~g} / \mathrm{d}(95 \% \mathrm{CI}=740-837)$ for calves in the control group. When pneumonia and otitis were analyzed separately, trace mineral treatment numerically decreased the incidence of pneumonia and otitis but these results were not statistically significant (Table 3).

\section{Blood Neutrophil and Monocyte Function}

Peripheral blood neutrophil function was greater for TMS-treated calves than for control calves at $14 \mathrm{~d}$ after birth; however, no difference existed in monocyte function (Figure 2). Briefly, TMS-treated calves had increased neutrophils activity, showing an increased mean fluorescence [i.e., increased number of ingested bacteria by neutrophils $(P=0.025)$ and percentage of neutrophils that performed phagocytosis $(P=0.079)$ compared with control calves]. Additionally, blood neutrophil and monocyte function was not different for calves that were recorded with pneumonia, otitis, or diarrhea, and calves that died before the end of the study period compared with healthy calves that survived during the study period (Figure 3).

\section{Oxidative Stress and Acute-Phase Protein Markers}

Calves supplemented with trace minerals had increased $(P=0.03)$ GPx activity compared with control calves at d 14 after birth (Figure 4). Calves with pneumonia had increased GPx activity $(P<0.05)$ at d 3 after birth and reduced GPx activity $(P<0.05)$ on d 35 after birth compared with healthy counterparts (Figure 4). Moreover, calves with otitis had greater GPx activity $(P<0.05)$ on d 35 after birth than calves without otitis (Figure 4). Calves that died had increased GPx activity $(P<0.05)$ on d 3 after birth compared with calves that survived during the study (Figure 4). No effects of treatment on serum SOD activity and Hp optical density were detected at d 3, 14, and 35 after birth (Figures 5 and 6 ). Moreover, no effects of disease on calves' serum SOD activity and haptoglobin optic density were detected (Figures 5 and 6 ). 

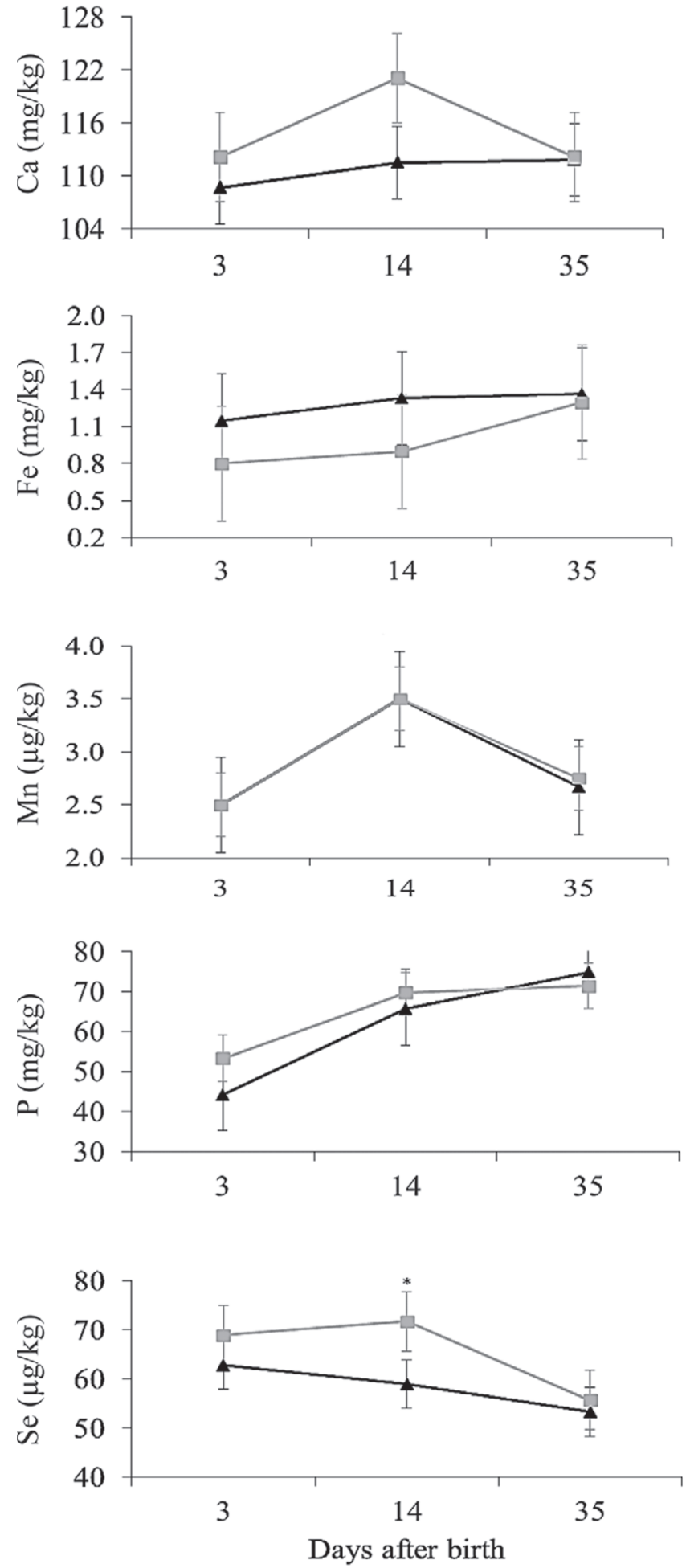
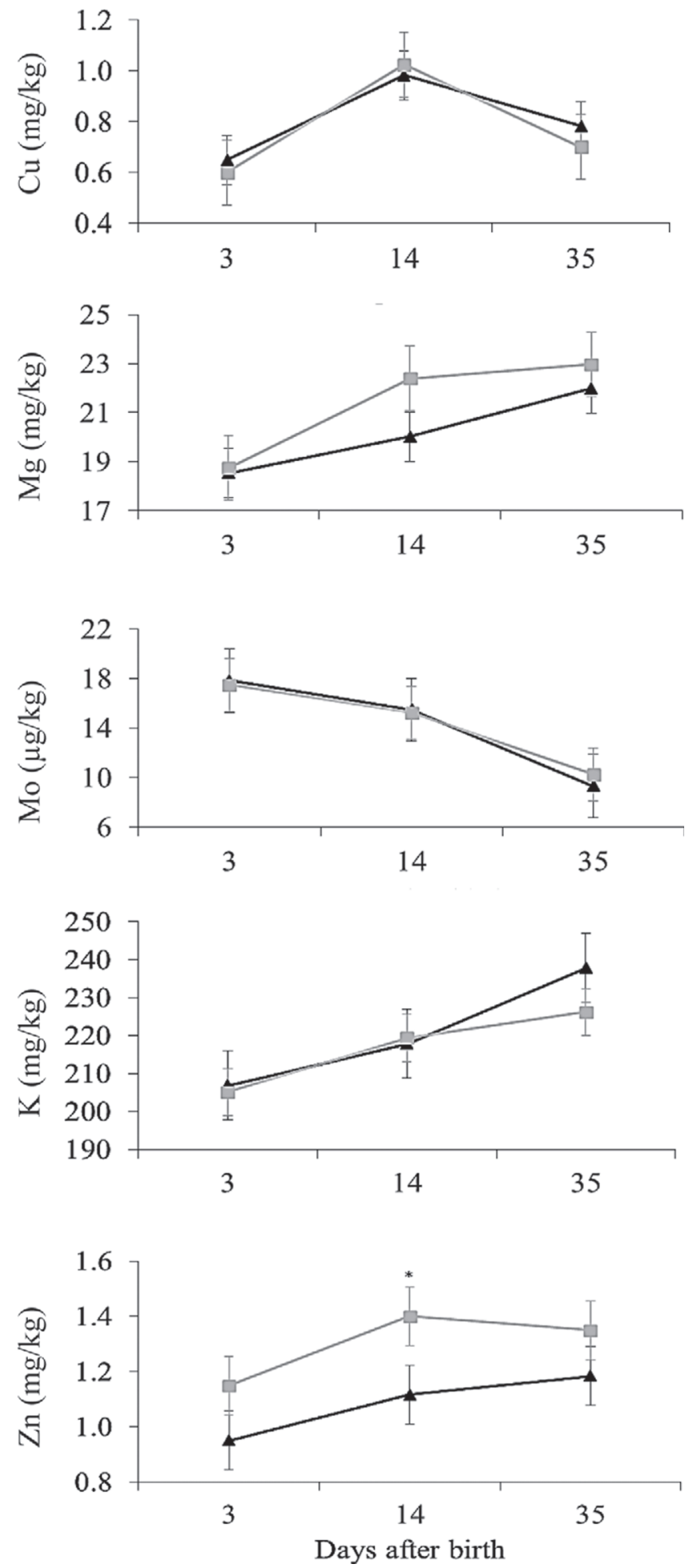

Figure 1. Effect of trace mineral supplement (TMS; 3 and $30 \mathrm{~d}$ of life) injections on serum concentrations at d 3, 14, and 35 after birth. The black lines represent calves in the control group and the light-gray lines represent calves in TMS group. Trace mineral-supplemented calves had greater serum concentrations of Se and $\mathrm{Zn}$ on d 14 after birth. Error bars represent SEM; * indicates $P<0.5$. 
Table 3. Effect of treatment on health events, evaluated using a mixed logistic regression model ${ }^{1}$

\begin{tabular}{|c|c|c|c|c|}
\hline \multirow[b]{2}{*}{ Health event } & \multicolumn{2}{|c|}{ Adjusted incidence (\%) } & \multirow{2}{*}{$\begin{array}{l}\text { Adjusted odds ratio } \\
\qquad(95 \% \mathrm{CI})\end{array}$} & \multirow[b]{2}{*}{$P$-value } \\
\hline & $\mathrm{TMS}^{2}$ & Control & & \\
\hline Mortality & 3.8 & 2.7 & $0.70(0.30-1.58)$ & 0.40 \\
\hline Diarrhea $^{3}$ & 41.7 & 49.7 & $1.38(1.02-1.86)$ & 0.03 \\
\hline Otitis & 10.6 & 13.2 & $1.26(0.82-2.01)$ & 0.31 \\
\hline Pneumonia & 35.2 & 40.0 & $1.23(0.91-1.65)$ & 0.18 \\
\hline $\mathrm{CPO}^{4}$ & 41.6 & 49.1 & $1.35(1.00-1.83)$ & 0.05 \\
\hline
\end{tabular}

${ }^{1}$ Adjusted odds ratio and adjusted probabilities of pneumonia; otitis; diarrhea; combined incidence of pneumonia, otitis, or both (CPO); and mortality were obtained using the LSMEANS statement in SAS (SAS Institute Inc., Cary, NC). Adjusted odds ratios are presented with the respective $95 \%$ CI.

${ }^{2}$ Trace mineral supplement (TMS)-treated calves were treated at 3 and $30 \mathrm{~d}$ of age.

${ }^{3}$ Diarrhea $=$ calves were affected with diarrhea for at least $3 \mathrm{~d}$.

${ }^{4} \mathrm{CPO}=$ this health event is characterized by calves that were affected with otitis or pneumonia, or both.

\section{DISCUSSION}

Supplementation with injectable trace minerals at early postnatal life was beneficial to calf immunity and oxidative stress status. Calves supplemented with trace minerals had improved neutrophil function, increasing the ability to perform phagocytosis, and improved glutathione peroxidase activity. Ultimately, supplemented calves had lower incidence of diarrhea and a lower incidence of combined diseases (including calves diagnosed with pneumonia, otitis, or both).

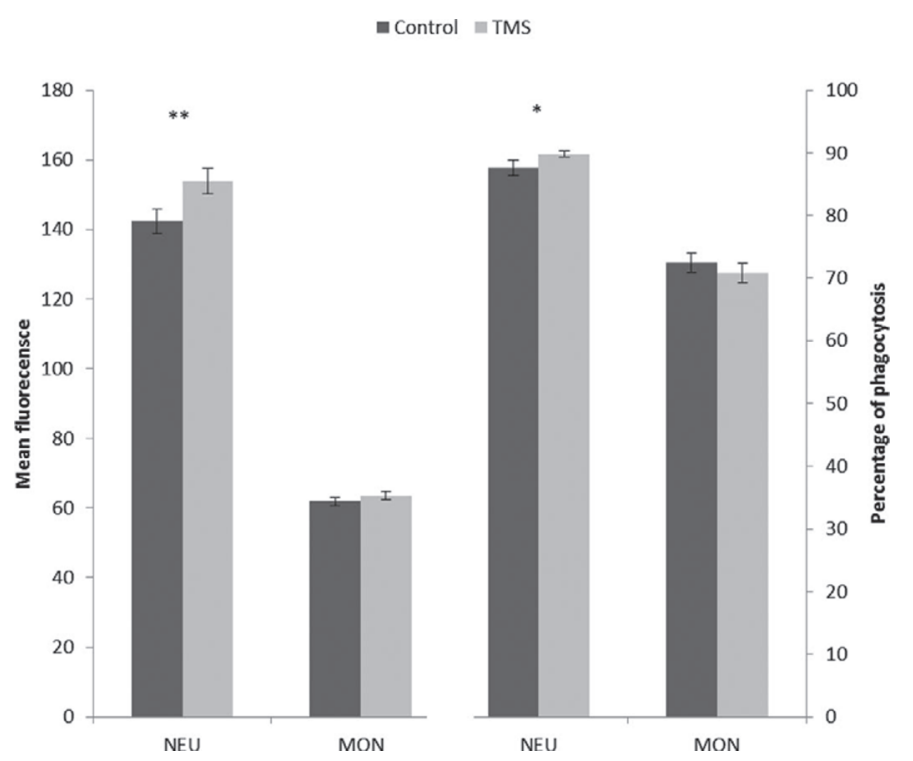

Figure 2. Effect of trace mineral supplement (TMS; 3 and $30 \mathrm{~d}$ of life) injections on the mean fluorescence intensity (left y-axis; reflecting ingested bacteria) and percentage of cells [neutrophils (NEU) and monocyte $(\mathrm{MON})]$ that performed phagocytosis (right y-axis). The dark-gray bars represent calves in the control group and the light-gray bars represent calves in the TMS group. Trace mineral-supplemented calves had greater overall neutrophil mean compared with control calves. Error bars represent SEM; * indicates $0.10>P \geq 0.05$; ** indicates $P<0.5$.
Trace minerals have an essential role in ensuring efficient immunocompetence in animals. Enjalbert et al., (2006) reported that marginal and deficient levels of trace minerals can increase risk of disease in adult cattle (metritis, mastitis, and lameness) and calves. A recent study reported a lower incidence of mastitis, decreased SCC, and lower incidence of endometritis for multiparous cows supplemented with an injectable trace mineral solution containing $\mathrm{Zn}, \mathrm{Cu}, \mathrm{Mn}$, and Se (Machado et al., 2013). Additionally, supplementation of trace minerals for calves have been extensively study in calves and its response to transportation (Spears, 1996), vaccination (Mandal et al., 2007), and white muscle disease (Schubert et al., 1961).

Trace minerals such as $\mathrm{Se}, \mathrm{Zn}$, and $\mathrm{Cu}$ are required for functioning of enzymes involved in the antioxidant defense system and may also affect immune cells through mechanisms distinct from antioxidant properties (Rotruck et al., 1973). Selenium is an essential component of GPx enzymes destroying hydrogen peroxide and lipid hydroperoxides (Rotruck et al., 1973). Copper and $\mathrm{Zn}$ form the $\mathrm{Cu}-\mathrm{Zn}$ superoxide SOD, which is responsible for dismutation of superoxide radicals to hydrogen peroxide in the cytosol (Halliwell, 1999). Zinc also induces synthesis of a metal-binding protein that may scavenge hydroxide radicals called metallothionein (Prasad, 2004). In addition to an antioxidant role, Zn may affect immunity via its important role in cell replication and proliferation (Spears and Weiss, 2008). The increased activity of the GPx enzyme suggests that the trace mineral supplementation can effectively reduce oxidative stress in calves in the first $2 \mathrm{wk}$ of life. Considering the particular immune cell sensitivity to oxidative stress (Mittler, 2002), it is possible that the improved phagocytosis ability of neutrophils in the current study was a function of the enhanced antioxidant status provided by the TMS.

Phagocytosis is one of the most important functions of the neutrophils, playing a critical role in their ability 

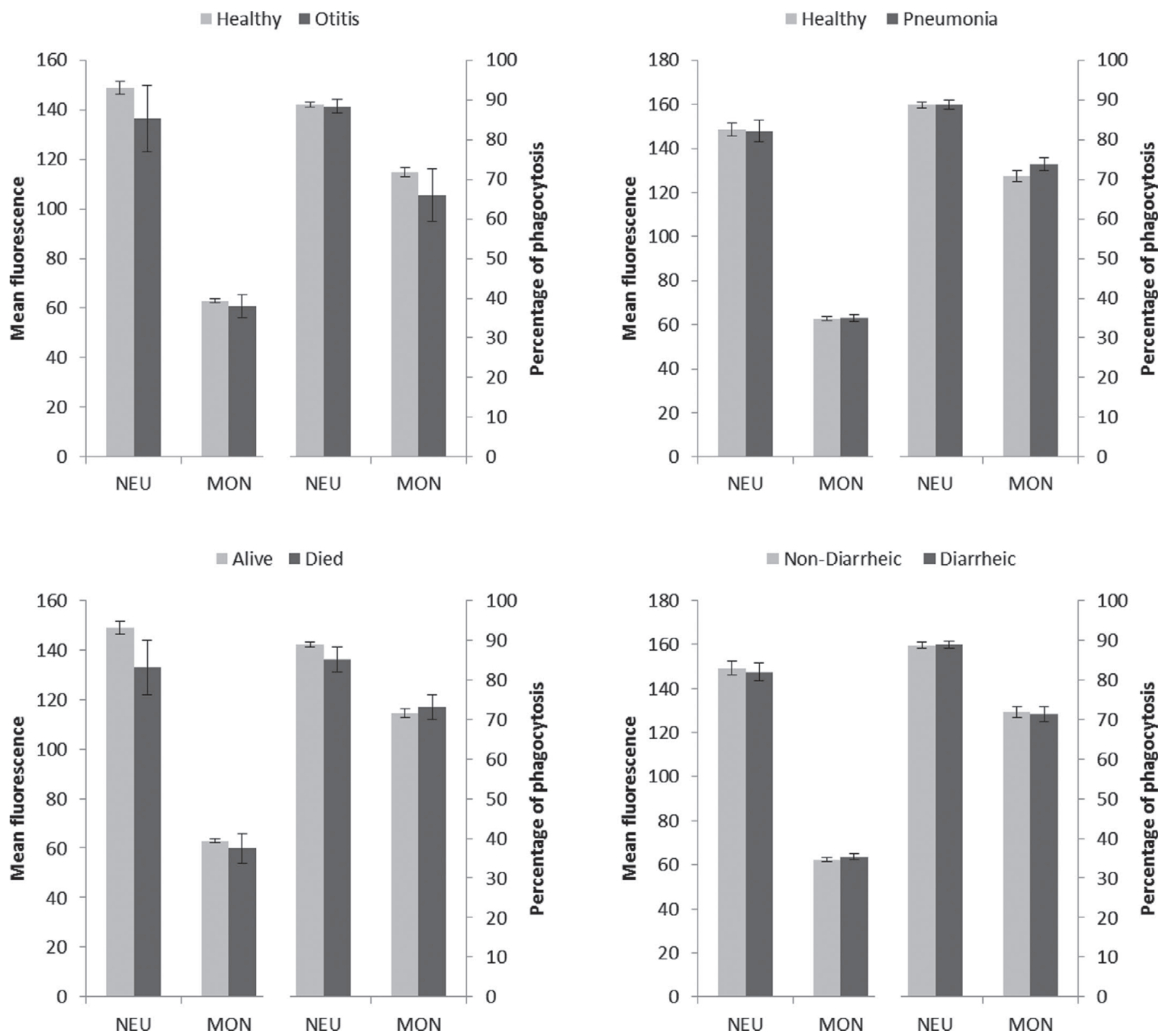

Figure 3. Mean fluorescence intensity (left y-axis; reflecting ingested bacteria) and percentage of performed phagocytosis (right y-axis) of neutrophils (NEU) and monocytes (MON) assessed on blood samples collected at $14 \mathrm{~d}$ of life. The dark-gray bars represent calves that were affected with otitis, pneumonia, diarrhea, and calves that died and light-gray bars represent calves that were not affected with disease and survived until the end of the study $(50 \mathrm{~d})$. Error bars represent SEM.

to recognize and eliminate foreign and infected cells. The effect of Se supplementation was already described to improve phagocytosis in white blood cell populations (Hogan et al., 1990). Moreover, Suwanpanya et al. (2007) reported an increase in the neutrophil phagocytic activity of Staphylococcus aureus in heifers dietary supplemented with $3 \mathrm{mg}$ of Se and 4,000 IU of vitamin E per day. In the current study, 14 d-old-calf peripheral blood neutrophils were tested against opsonized E. coli and the results indicated significant improvement in the phagocytic activity for calves supplemented with trace minerals including Se at $3 \mathrm{~d}$ of life compared with nonsupplemented calves. Although trace mineral supplementation significantly increased GPx activity at $14 \mathrm{~d}$ of age in this study, no effect of treatment was observed at $35 \mathrm{~d}$ of life. Interestingly, the current study reported decreased GPx activity for calves diagnosed with pneumonia and increased activity for calves diagnosed with 

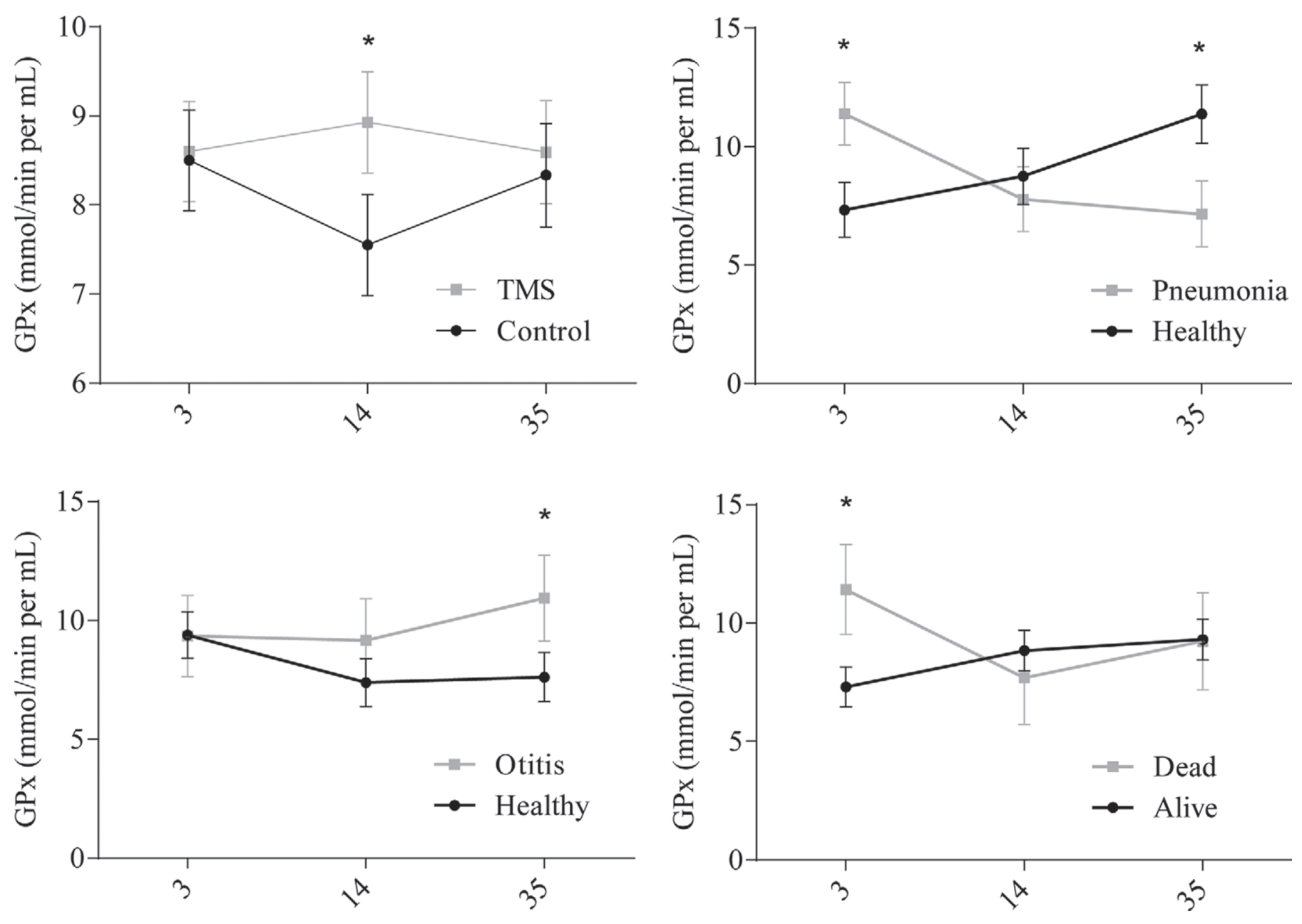

Figure 4. Plasma glutathione peroxidase (GPx) activity (nmol/min per milliliter) was assessed on d 3, 14, and 35 of the calves' lives. The light-gray lines represent the effects of trace mineral supplement (TMS)-treated calves (vs. control calves), calves with pneumonia, calves with otitis, and calves that died on the repeated measurements of GPx. The black lines represent calves that survived until the end of the study period $(50 \mathrm{~d})$. Error bars represent SEM; * indicates $P<0.05$.

otitis. Cemek et al. (2006) reported similar results in an investigation of antioxidant status in children with acute pneumonia, where GPx activity was reduced in affected children compared with nonaffected children. Additionally, another study using human infants found a decreased level of plasma GPx activity in 57 patients with pneumonia compared with 87 controls (Cui et al., 1997).

Bonham et al. (2002) suggested that neutrophil function might be a valuable biomarker for $\mathrm{Cu}$ status. In the current study, supplemental trace minerals did not influence SOD, the antioxidant enzyme that uses $\mathrm{Cu}$ and $\mathrm{Zn}$ to be synthesized. Likewise, Hp, a marker of acute-phase proteins, was not affected by treatment. Acute-phase proteins are well described as quantifiable indicators of inflammation of infection in adult cattle. However, some factors exist that can significantly change acute-phase protein concentrations in neonatal calves, such as stress of birth, microbial challenge, and intake of colostral cytokines.

The beneficial effects of trace mineral supplementation on immune function were likely associated with the lower incidence of diarrhea and CPO. Oral Zn supplementation was reported to reduce the incidence of diarrhea among children in developing countries (Fuchs, 1998; Hambidge, 2000). Furthermore, the effectiveness of $\mathrm{Zn}$ to reduce diarrhea in children was related to improvement in the enzymatic functions of the brush borders, and enhancement of the intestinal mucosa repair (Sazawal et al., 1995: Strand et al., 2002). Moreover, Berger et al. (2006) reported a significant reduction of nosocomial pneumonia by intravenous multi-trace element supplements $(\mathrm{Cu}, \mathrm{Se}$, and $\mathrm{Zn})$ in severely burned patients. Selenium is one of the trace minerals frequent- 

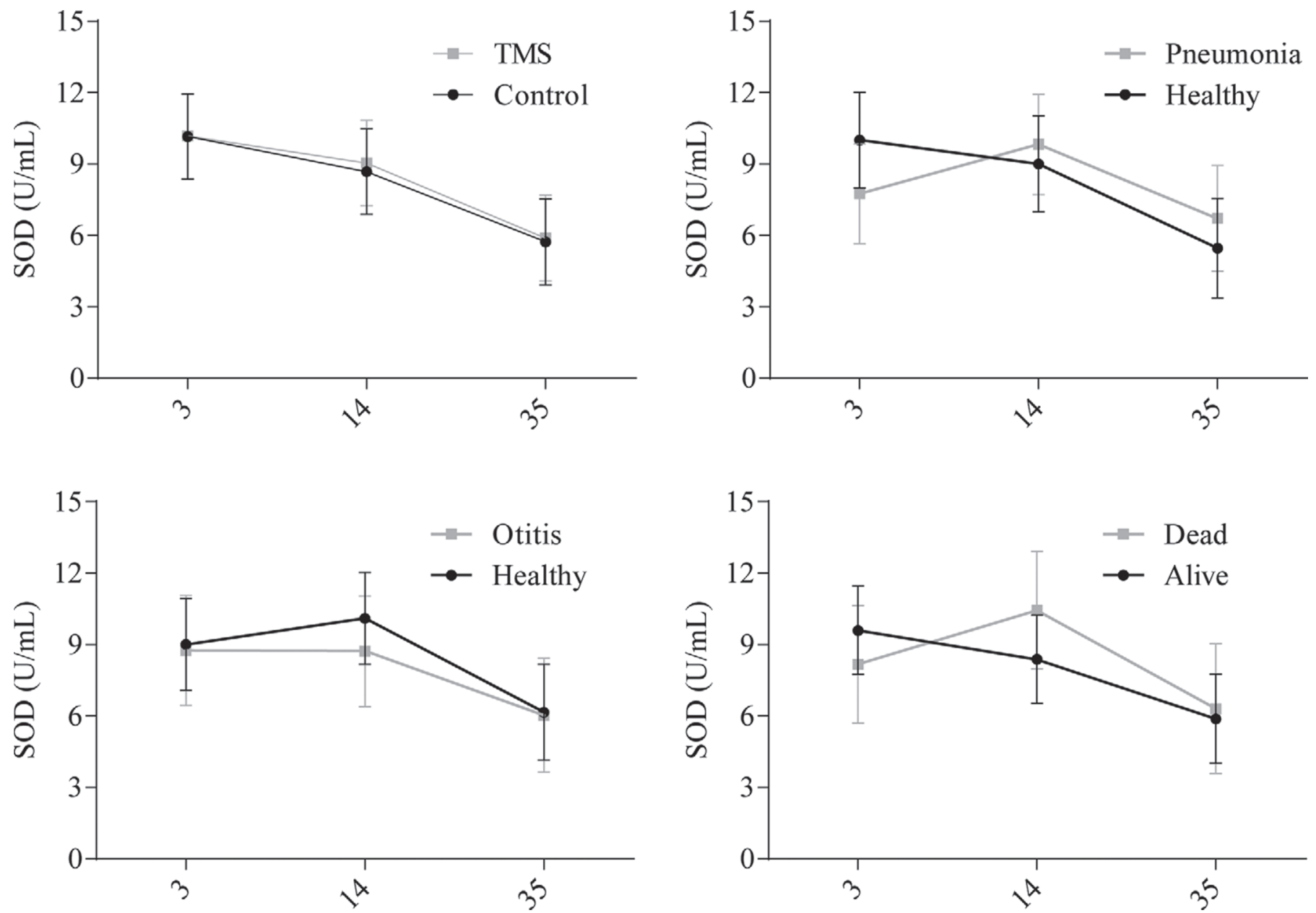

Figure 5. Serum superoxide dismutase (SOD) activity $(\mathrm{U} / \mathrm{mL})$ was assessed on d 3, 14, and 35 of the calves' lives. The light-gray lines represent the effects of trace mineral supplement (TMS) treatment, pneumonia, otitis, and calves that died on the repeated measurements of SOD. The black lines represent calves that were healthy and survived until the end of the study period (50 d). No effect was observed on SOD activity for TMS-treated calves (vs. control calves), pneumonic calves (vs. healthy), calves diagnosed with otitis (vs. healthy), and calves that survived until the end of the study period (vs. calves that died). Error bars represent SEM.

ly associated with improved immunity and reduction of diseases (Rayman, 2000). Selenoenzymes are ubiquitous in mammalian cells, having 2 major roles. First, the selenoenzymes have antioxidant properties that protect cell components such as membranes, enzymes, proteins, and DNA. Second, selenoenzymes inhibit proinflammatory cell metabolisms by reducing the peroxide tone of intracellular water (Rayman, 2000).

The benefits of trace mineral supplementation herein reported did not translate into improved ADG. Clearly, within a calf-rearing program, a multitude of factors can play a role in the growth performance of calves. Although neutrophil function and oxidative stress status were improved in TMS-treated calves during the first 2 wk of life and the incidences of diarrhea and $\mathrm{CPO}$ were reduced, the absence of effects on ADG and survivability for TMS-treated calves warrants further investigation.

\section{CONCLUSIONS}

Trace minerals supplementation improved neutrophil function and GPx activity of dairy calves in the first 2 wk after birth. Moreover, TMS-treated calves had reduced incidence of diarrhea and CPO. However, the benefits for immunity-related parameters and health did not translate into improved growth performance and reduced mortality in the first $50 \mathrm{~d}$ of life. Future research should focus on the investigation of the length and magnitude of trace mineral supplementation needed to sustain an appropriate immunological status in the preweaning period to maximize health benefits and growth performance of dairy calves. 

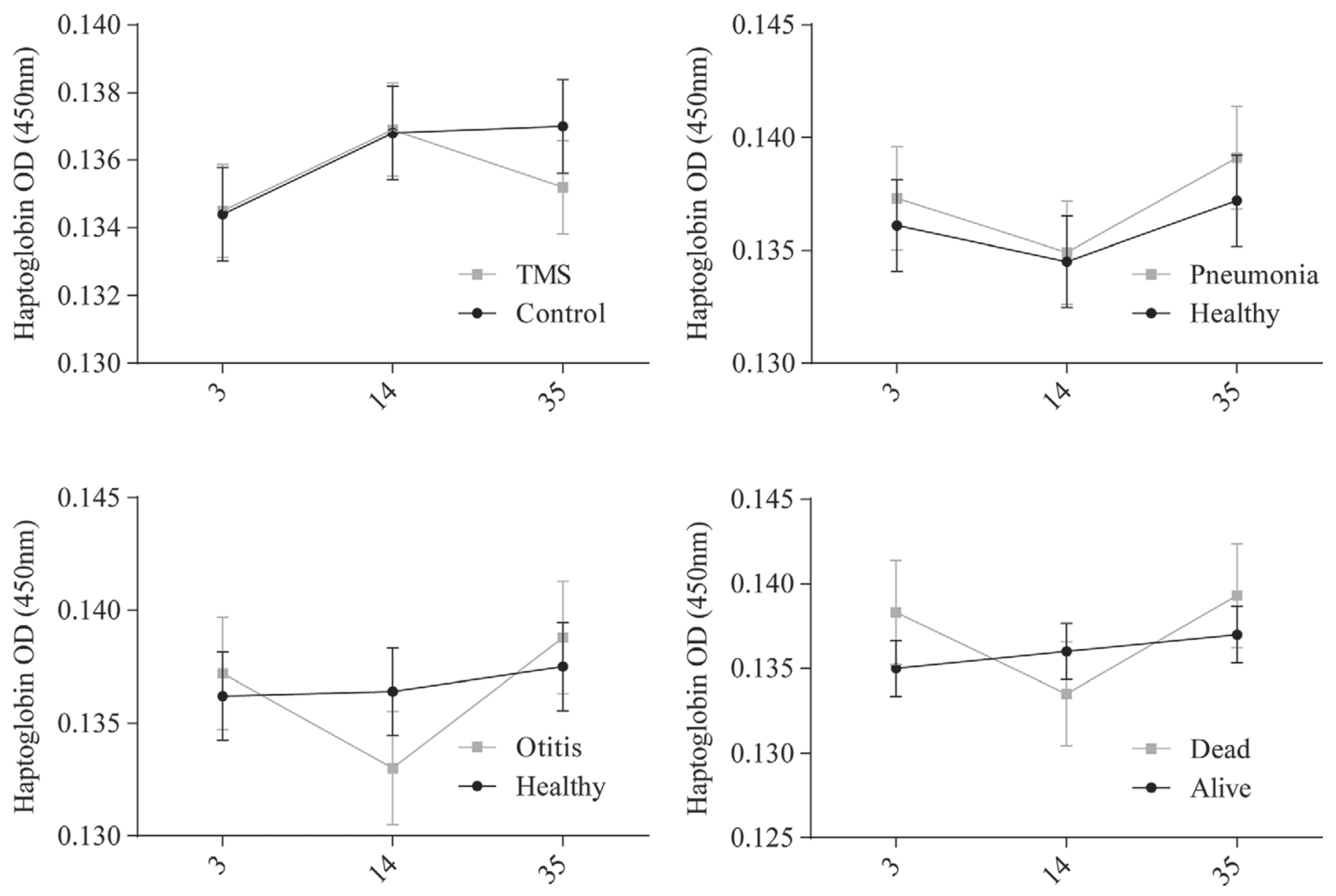

Figure 6. Serum haptoglobin (Hp) optical density (OD) was evaluated on d 3, 14, and 35 of calves' lives. The light-gray lines represent the effect of trace mineral supplement (TMS) treatment, pneumonia, otitis, and calves that died on the repeated measurements of superoxide dismutase. The black lines represent calves that were healthy and survived until the end of the study period (50 d). No effect was observed on Hp OD for TMS-treated calves (vs. control calves), pneumonic calves (vs. healthy), calves diagnosed with otitis (vs. healthy), and calves that survived until the end of the study period (vs. calves that died). Error bars represent SEM.

\section{REFERENCES}

Berger, M. M., P. Eggimann, D. K. Heyland, R. L. Chioléro, J.-P. Revelly, A. Day, W. Raffoul, and A. Shenkin. 2006. Reduction of nosocomial pneumonia after major burns by trace element supplementation: Aggregation of two randomised trials. Crit. Care 10:R153.

Bonham, M., J. M. O'Connor, B. M. Hannigan, and J. J. Strain. 2002 The immune system as a physiological indicator of marginal copper status? Br. J. Nutr. 87:393-403.

Carroll, J. A., and N. E. Forsberg. 2007. Influence of stress and nutrition on cattle immunity. Vet. Clin. North Am. Food Anim. Pract. 23:105-149.

Cemek, M., H. Çaksen, F. Bayiroğlu, F. Cemek, and S. Dede. 2006. Oxidative stress and enzymic-non-enzymic antioxidant responses in children with acute pneumonia. Cell Biochem. Funct. 24:269273.

Crookshank, H. R., M. H. Elissalde, R. G. White, D. C. Clanton, and H. E. Smalley. 1979. Effect of transportation and handling of calves upon blood serum composition. J. Anim. Sci. 48:430-435.

Cui, H., S. Yin, H. Gao, and G. Li. 1997. The comparison of selenium status between the children suffered from pneumonia and the normal children from kindergarten. Wei Sheng Yan Jiu 26:242-244.

Enjalbert, F., P. Lebreton, and O. Salat. 2006. Effects of copper, zinc and selenium status on performance and health in commer- cial dairy and beef herds: Retrospective study. J. Anim. Physiol. Anim. Nutr. (Berl.) 90:459-466.

Fuchs, G. J. 1998. Possibilities for zinc in the treatment of acute diarrhea. Am. J. Clin. Nutr. 68(Suppl.):480S-483S.

Galyean, M. L., L. J. Perino, and G. C. Duff. 1999. Interaction of cattle health/immunity and nutrition. J. Anim. Sci. 77:1120-1134.

Halliwell, B. 1999. Antioxidant defense mechanisms: From the beginning to the end (of the beginning). Free Radic. Res. 31:261-272.

Hambidge, M. 2000. Human zinc deficiency. J. Nutr. 130:1344S1349S.

Hogan, J. S., K. L. Smith, W. P. Weiss, D. A. Todhunter, and W. L. Schockey. 1990. Relationships among vitamin E, selenium, and bovine blood neutrophils. J. Dairy Sci. 73:2372-2378.

Lombard, J. E., F. B. Garry, S. M. Tomlinson, and L. P. Garber. 2007. Impacts of dystocia on health and survival of dairy calves. J. Dairy Sci. 90:1751-1760.

Lundborg, G. K., P. A. Oltenacu, D. O. Maizon, E. C. Svensson, and P. G. A. Liberg. 2003. Dam-related effects on heart girth at birth, morbidity and growth rate from birth to 90 days of age in Swedish dairy calves. Prev. Vet. Med. 60:175-190.

Machado, V. S., M. L. S. Bicalho, R. V. Pereira, L. S. Caixeta, W. A Knauer, G. Oikonomou, R. O. Gilbert, and R. C. Bicalho. 2013. Effect of an injectable trace mineral supplement containing selenium, copper, zinc, and manganese on the health and production of lactating Holstein cows. Vet. J. 197:451-456. 
Makimura, S., and N. Suzuki. 1982. Quantitative determination of bovine serum haptoglobin and its elevation in some inflammatory diseases. Nihon Juigaku Zasshi 44:15-21.

Mandal, G. P., R. S. Dass, D. P. Isore, A. K. Garg, and G. C. Ram. 2007. Effect of zinc supplementation from two sources on growth, nutrient utilization and immune response in male crossbred cattle (Bos indicus $\times$ Bos taurus) bulls. Anim. Feed Sci. Technol. $138: 1-12$

Mittler, R. 2002. Oxidative stress, antioxidants and stress tolerance. Trends Plant Sci. 7:405-410.

Nockels, C. F., J. DeBonis, and J. Torrent. 1993. Stress induction affects copper and zinc balance in calves fed organic and inorganic copper and zinc sources. J. Anim. Sci. 71:2539-2545.

Ollivett, T. L., D. V. Nydam, T. C. Linden, D. D. Bowman, and M. E. Van Amburgh. 2012. Effect of nutritional plane on health and performance in dairy calves after experimental infection with Cryptosporidium parvum. J. Am. Vet. Med. Assoc. 241:1514-1520.

Orr, C. L., D. P. Hutcheson, R. B. Grainger, J. M. Cummins, and R. E. Mock. 1990. Serum copper, zinc, calcium and phosphorus concentrations of calves stressed by bovine respiratory disease and infectious bovine rhinotracheitis. J. Anim. Sci. 68:2893-2900.

Pogge, D. J., E. L. Richter, M. E. Drewnoski, and S. L. Hansen. 2012. Mineral concentrations of plasma and liver after injection with a trace mineral complex differ among Angus and Simmental cattle. J. Anim. Sci. 90:2692-2698.

Prasad, M. 2004. Metallothioneins, metal binding complexes and metal sequestration in plants. Pages $47-83$ in Heavy Metal Stress in Plants: From Biomolecules to Ecosystems. M. N. V. Prasad, ed. Springer-Verlag, Berlin, Germany.

Rayman, M. P. 2000. The importance of selenium to human health. Lancet 356:233-241.

Rotruck, J. T., A. L. Pope, H. E. Ganther, A. B. Swanson, D. G. Hafeman, and W. G. Hoekstra. 1973. Selenium: Biochemical role as a component of glutathione peroxidase. Science 179:588-590.
Sazawal, S., R. E. Black, M. K. Bhan, N. Bhandari, A. Sinha, and S. Jalla. 1995. Zinc supplementation in young children with acute diarrhea in India. N. Engl. J. Med. 333:839-844.

Schubert, J. R., O. H. Muth, J. E. Oldfield, and L. F. Remmert. 1961. Experimental results with selenium in white muscle disease of lambs and calves. Fed. Proc. 20:689-694.

Soberon, F., E. Raffrenato, R. W. Everett, and M. E. Van Amburgh. 2012. Preweaning milk replacer intake and effects on long-term productivity of dairy calves. J. Dairy Sci. 95:783-793.

Sordillo, L. M., and S. L. Aitken. 2009. Impact of oxidative stress on the health and immune function of dairy cattle. Vet. Immunol. Immunopathol. 128:104-109.

Spears, J. W. 1996. Organic trace minerals in ruminant nutrition. Anim. Feed Sci. Technol. 58:151-163.

Spears, J. W. 2000. Micronutrients and immune function in cattle. Proc. Nutr. Soc. 59:587-594.

Spears, J. W., and W. P. Weiss. 2008. Role of antioxidants and trace elements in health and immunity of transition dairy cows. Vet. J. $176: 70-76$.

Strand, T. A., R. K. Chandyo, R. Bahl, P. R. Sharma, R. K. Adhikari, N. Bhandari, R. J. Ulvik, K. Mølbak, M. K. Bhan, and H. Sommerfelt. 2002. Effectiveness and efficacy of zinc for the treatment of acute diarrhea in young children. Pediatrics 109:898-903.

Suwanpanya, N., W. Wongpratoom, M. Wanapat, S. Aiumlamai, S. Wittayakun, and C. Wachirapakorn. 2007. The influence of bovine neutrophils on in vitro phagocytosis and killing of Staphylococcus aureus in heifers supplemented with selenium and vitamin E. Songklanakarin J. Sci. Technol. 29:696-706.

Weaver, D. M. J. W. Tyler, D. C. VanMetre, D. E. Hostetler, and G. M. Barrington. 2000. Passive transfer of colostral immunoglobulins in calves. J. Vet. Intern. Med. 14:569-577. 